\title{
Endoscopic Transaqueductal Removal of Neurocysticercosis
}

\author{
Viroj WIWANITKIT \\ Surin Rajabhat University, Surin, Thailand
}

To the Editor:

$\mathrm{T}$ The report on "Endoscopic Transaqueductal Removal of Neurocysticercosis" is very interesting (1). Chen et al. reported that "endoscopic transaqueductal removal of the fourth ventricular cysticercosis with a flexible neuroendoscope should be recommended as the optimal choice of the disease due to its minimal invasion, fewer complications, shorter length of stay and cheaper treatment costs (1)."

In fact, the endoscopic technique for management of neurocysticercosis is not new. It has been proposed for many years. Husain et al. noted that "Transaqueductal removal of an intrafourth ventricular cyst along with endoscopic third ventriculostomy with a rigid endoscope and catheter is an effective treatment and obviates the need for posterior cranial fossa exploration (2)." Suri et al. also reported the success in use of this technique with internal cerebrospinal fluid diversion via endoscopic third ventriculostomy (4).

However, there are many concerns on this technique. First, the experienced endoscopist is required and this is not easily available. Second, there has never been cost analysis; hence, it might be too preliminary to conclude that the technique is cheaper than standard technique. Third, the long term follow up on the requirement of re-manipulation is needed. In the report of using this technique in neonate, in long term followup, the rate of requirement of re-manipulation is high (about $10 \%)(3)$.

\section{REFERENCES}

1. Chen G, Xiao Q, Zheng J, Wu J, Ao Q, Liu Y: Endoscopic transaqueductal removal of fourth ventricular neurocysticercosis: Report of three cases. Turk Neurosurg 25:488-492, 2015

2. Husain M, Rastogi M, Jha DK, Husain N, Gupta RK: Endoscopic transaqueductal removal of fourth ventricular neurocysticercosis with an angiographic catheter. Neurosurgery 60:249-253, 2007

3. Schulz M, Bührer $C$, Spors B, Haberl H, Thomale UW: Endoscopic neurosurgery in preterm and term newborn infants-a feasibility report. Childs Nerv Syst 29:771-779, 2013

4. Suri A, Goel RK, Ahmad FU, Vellimana AK, Sharma BS, Mahapatra AK: Transventricular, transaqueductal scope-in-scope endoscopic excision of fourth ventricular neurocysticercosis: A series of 13 cases and a review. J Neurosurg Pediatrics 1:35-39, 2008 